\title{
UM MUNDO EM DESTROÇOS: RUÍNAS, RESTOS E ESCRITA DE SI EM NARRATIVAS ESCRITAS E VISUAIS DO OCEANO ÍNDICO
}

\author{
A WORLD OF DEBRIS: RUINS, REMAINS AND \\ SELF-WRITING IN VISUAL AND WRITTEN \\ NARRATIVE OF THE INDIAN OCEAN
}

Elena Brugioni 
Resumo :Abordando os debates críticos que caracterizam a pesquisa no âmbito dos estudos do oceano Índico, bem como no campo das literaturas africanas e do debate sobre literatura-mundial (world-literature WReC), este artigo apresenta uma reflexão sobre a ideia de ruínas, restos - debris - e escrita de si - self-writing - como dispositivos estéticos e conceituais por meio dos quais narrativas visuais e literárias registram o passado e problematizam o futuro, sugerindo novas possibilidades críticas para abordar e analisar formas de narrar e imaginar o presente e a subjetividade no âmbito do que se define como literaturas do oceano Índico.

Palavras-chave: Literaturas Africanas; Estudos do Oceano Índico; Literatura-Mundial; restos, ruínas e escrita de si. 
Abstratc: Addressing critical debates that characterize the scholarship on Indian Ocean studies, as well as the field of African Literatures and the debate on world-literature (WReC), this article presents a reflection on the idea of ruins, remains - debris - and self-writing as aesthetic and conceptual devices through which visual and literary narratives register the past and problematize the future, suggesting new critical paths to approach and analyze forms of narrating and imagining the present within the perspective of Indian ocean literatures.

Keywords: African literatures; Indian Ocean studies; world-literature; ruins, remains and self-writing 
1. Narrativas literárias e visuais no Oceano Índico

Abordando os debates críticos que caracterizam a pesquisa no âmbito dos estudos do oceano Índico, bem como no campo das literaturas africanas e da literatura-mundial (world-literature), pretendo desenvolver uma reflexão sobre a ideia de ruínas, restos - debris - e escrita de si - self-writing - a serem entendidos como dispositivos estéticos e conceituais por meio dos quais narrativas visuais e literárias registram o passado e problematizam o futuro, sugerindo novas possibilidades críticas para abordar e analisar formas de narrar e imaginar a condição do presente no mundo do Índico. ${ }^{1}$

0 ponto de partida da reflexão que me proponho desenvolver é o projeto fotográfico e o fotolivro Mosquito Coast. Travels from Maputo to Mogadishu de autoria de Guillaume Bonn (2015) e as obras literárias de autores contemporâneos como Nurrudin Farah (Somália), Abdulrazak Gurnah (Tanzânia) e João Paulo Borges Coelho (Moçambique). O contraponto entre narrativa fotográfica e literária oferece a possibilidade de (re)definir formas de narração - visual ${ }^{1} 0$ texto aqui apresentado resulta das pesquisas desenvolvidas no âmbito do projeto "Comparativismos Combinados e Desiguais. Repensar o campo dos estudos literários africanos e pós-coloniais à luz do debate sobre literatura-mundial" (Ref. 2020/07836-0) financiado pela Fundação de Amparo à Pesquisa do Estado de São Paulo - FAPESP. 
e literária - que, de acordo com a reflexão proposta por Ann Laura Stoler, encaram as ruínas não como objetos do olhar melancólico pós-imperial, mas como "pontos de vista estratégicos para repensar as formações imperiais e seus significados contemporâneos" (Stoler, 2013; 2016). Dentro desta perspectiva, o Oceano Índico sobressai como um dispositivo estético e conceitual capaz de arruinar a ruína (cf. to ruin, ruination; Stoler, 2013) e, simultaneamente, como um paradigma crítico que evidencia e focaliza a re(a) presentação vital e presente dos restos inertes dos impérios passados (Stoler, 2016), configurando estas formas de narrar como "espaço[s] intelectual[ais] para repensarmos aquelas temporalidades que estão, sempre simultaneamente, se ramificando em diversos futuros, e ao fazerem isso abrem caminhos para a possibilidade de múltiplas ancestralidades" (Mbembe, 2002). Desta forma, o espaço geográfico e imaginário do Oceano Índico é (re)modelado como um elemento narrativo e visual e, simultaneamente, como um ponto de vista estratégico para o surgimento de (outras) histórias do eu e do mundo indispensáveis para repensar as múltiplas possibilidades e práticas narrativas e de imaginação dentro do que foi recentemente definido como "Afrique-Monde" (Mbembe \& Sarr, 2017). Ao mesmo tempo, o percurso proposto neste artigo pretende estabelecer diálogos críticos e interseções disciplinares entre campos de estudos 
distintos tais como os que caracterizam os estudos do Oceano Índico e o campo das Literaturas Comparadas, com particular enfoque no debate que caracteriza os estudos de Literatura-Mundial (world-literature), de acordo com a perspectiva desenvolvida pelo Coletivo de Pesquisa de Warwick (WReC) cuja (re) definição do debate comparatista numa perspectiva crítica e conceitual de matriz materialista (WReC, 2015) proporciona solicitações significativas e de grande potencialidade teórica e conceitual para o debate que configura o campo das Literaturas Africanas e dos Estudos Literários do Oceano Índico.

Mosquito Coast. Travels from Maputo to Mogadishu (Bonn, 2015) é um projeto fotográfico documental - e um fotolivro publicado em 2015 - desenvolvido por Guillaume Bonn, fotógrafo e artista visual de destaque no campo da fotografia contemporânea nascido no Madagascar e com uma vasta carreira internacional e inúmeros projetos fotográficos no continente africano. Como mostra o título do projeto, este é livremente inspirado no popular livro de Paul Theroux, The Mosquito Coast (1981), romance ambientado na América Central, publicado originalmente em 1981 e posteriormente adaptado para o cinema; um livro que rapidamente se tornou um best seller de um dos mais renomados autores da literatura de viagem contemporânea; aliás, de acordo com alguns 
críticos, o verdadeiro herdeiro de narradores como Conrad e Hemingway. Todavia, não pretendo estabelecer aqui nenhum tipo de paralelismo entre o livro de Paul Theroux e o projeto fotográfico e o fotolivro de autoria de Bonn; ao mesmo tempo, o que parece sobressair como aspeto mais curioso é que a possível referência ao título do romance de Theroux é explicada por Bonn, tanto na descrição do Projeto quanto na Introdução do fotolivro, como um dos aspetos que caracteriza os diversos povos, regiões, países e sujeitos que habitam e define a costa oriental de África ou melhor o Índico africano²; malária e herança colonial seriam portanto o fio condutor de um percurso que junta diferentes lugares, cidades e países que se situam na orla do Índico: Moçambique, Quénia, Tanzânia e Somália. No entanto, na minha opinião, o que uma possível referência ao título do romance de Paul Theroux representa de forma muito mais evidente é uma clara analogia entre a obra fotográfica/visual de Bonn e o gênero da literatura de viagem, ${ }^{3}$ onde o continente africano se destaca como um paradigma geográfico e estético indiscutível. De fato, neste sentido, a produção de Paul Theroux, como habilmente mostra António Pinto Ribeiro no seu livro África, os Quatros Rios. A representação de África através da literatura

${ }^{2}$ Veja-se o excerto da Introdução do fotolivro de Bonn citado mais adiante neste texto.

${ }^{3}$ Veja-se, neste sentido, o prefácio ao fotolivro de autoria de Jon Lee Anderson in Bonn, 2015. 
de viagens europeia e norte-americana (2017), é um caso contemporâneo exemplar deste género literário, cuja tradição de longa data representa um campo de estudo e de produção crítica extremamente produtivo para problematizar a relação entre o eu e o outro, oferecendo a possibilidade de analisar a intersecção entre narrativa ficcional, documentária e escrita de $\mathrm{si}^{4}$ Seria portanto este o caso do que é geralmente considerado uma obra-prima da literatura ocidental moderna, e estou obviamente me referind o a Heart of Darkness de Joseph Conrad (1904); ao mesmo tempo seria possivelmente também o caso do projeto fotográfico de Guillaume Bonn que em seu fotolivro propõe uma narrativa visual que enreda narrativas ficcionais, documentais e autobiográficas mostrando, como afirma o escritor angolano Ruy Duarte de Carvalho, "Em viagem, portanto o narrador" (2005) sublinhando magistralmente a ligação inevitável entre a escrita de si e a literatura de viagem. ${ }^{5} \mathrm{E}$, de fato, essa dimensão do trabalho de Bonn torna-se particularmente emblemática sobretudo de um ponto de vista crítico se for abordada em contraste com a dimensão

\footnotetext{
${ }^{4}$ Pense-se a este propósito na preponderância da literatura de viagem nas reflexões teórica que pautam os estudos literários pós-coloniais, entre os quais cabe destacar o trabalho pioneiro de Edward W. Said em Cultura e Imperialismo (1993)

${ }^{5} \mathrm{Na}$ Introdução do fotolivro afirma Bonn: "Mosquito Coast is a visual notebook (...), and also a repository of memory." (Bonn, $2015, \mathrm{~s} / \mathrm{p}$ )
} 
memorialística e privada que orienta explicitamente Mosquito Coast. A este respeito, o fotógrafo afirma:

For many years I have been trying to come to terms with the changes that are transforming Africa into a place that is far removed from the familiar, comfortable Africa I knew as a child. Places that seems frozen in time; places that reminded me of the colonial-era houses I had once lived in with my parents.

I am the third generation of a family of Frenchmen born in Madagascar. My father and my grandfather spent their formative years on the island. My first memoirs are of Djibouti, an old French colonial outpost stuck between the Danakil Desert and the Indian Ocean. In my childhood in the seventies, it was still part of France. (...)

In time I become a documentary photographer. I lived in Nairobi and traveled to every corner of the continent, witnessing and recording the continent's changes as they took place. Along the way, my own particular sense of Africa emerged as well, an alchemical mixture made up of the familiar - its fading European colonial heritage, architecture, and enduring lifestyle - together with the continent's devastating wars, its dictatorships, and the epic destruction of its natural environment, including its wild-life. I wished to somehow capture all of this visually. The idea persisted. For a long time, I could not 
Immagine how to embark in such a project. I felt challenged by a number of seemingly unanswerable questions. I could I tell stories of my own memories of a world that no longer existed or, if it did, barely survived? How could I come to terms with my own family's role in the colonial brutality that the continent has experienced for a hundred years? How to avoid falling into the trap of all the romantic clichés of colonial Africa?

I have been trying to come to terms with the changes that are transforming Africa. We are told that progress is a good thing, that mobile phones and the Internet will make all of us happier and our lives better. Along with those things, skyscrapers, highways, parking lots, and all the other accouterments of consumerism have begun to find their way into Africa and to change it, sometimes disastrously. (Bonn, 2015, s/p) ${ }^{6}$

Ao lado do aspecto relacionado com as questões de "progresso e transformação" (Bonn 2015), sobre o qual voltarei na conclusão deste artigo, gostaria de me deter na narrativa visual proposta por Boon, observando como esta parece alcançar um sentido ulterior, ao articular a narrativa fotográfica com uma dimensão explicitamente autobiográfica que o autor

${ }^{6}$ Todas as citações de Guillaume Bonn são retiradas da Introdução do fotolivro The Mosquito Coast. Travels from Maputo to Mogadishu. Hatje Cantz. (Bonn, 2015, s/p). 
reconhece como a estratégia visual para por em relação um conjunto de lugares e cidades geograficamente distintas mas simultaneamente próxima; portanto, a dimensão subjetiva parece configurar-se como um dispositivo visual e narrativo para construir um mundo através do olhar fotográfico a ser entendido como uma linguagem de documentação e, simultaneamente, de auto-apresentação. A este respeito, refiro-me à possibilidade de abordar Mosquito Coast como um trabalho de escrita de si (self-writing) - o mundo do autor - bem como um trabalho sobre o contexto da África oriental a ser entendido como um local inscrito no sistema-mundo (world-system) (Wallerstein, 2004). A este propósito merece trazer mais uma passagem do texto de Introdução do fotolivro:

It is strange and difficult for me to see the content that I love, and that has made me and defined me, metamorphose so drastically.

\section{(...)}

I decided that I needed to go back where it all began, to the East African coastline, where, over the centuries, newcomers had arrived continuously from distant lands by boat, each bringing new influences with them and together creating the Africa I had grow up with. They came in waves, in trickles, and in different shape and hues. There were conquerors, explorers, traders, and immigrants, 
and they included Portuguese, Omanis, Indians, British, Italians, Germans, and Frenchs. I traveled from Mozambique northward along the Indian Ocean shoreline to Tanzania, Kenya, and Somalia. Subject to the varied forces of their own histories, each was also unique in their modern incarnation. One of the few things they always had in common is malaria, a mosquito-borne disease caused by a parasite which causes close to a million deaths every year, the majority of them in Africa. Another thing they share is colonial heritage. (Bonn, 2015, s/p).

Observando algumas das imagens que integram o Projeto, em consonância com o sentimento de dor, tristeza e nostalgia que o fotógrafo admite na Introdução, ecoando o que Susan Sontag define como a dimensão elegíaca intrínseca do ato de fotografar (1977), ruínas e destroços têm um significado estético e conceitual emblemático - um cronótopo visual na obra de Bonn -, apontando, na minha opinião, para a reflexão proposta por Ann Laura Stoler sobre os destroços dos impérios - imperial debris - (Stoler, 2013; 2016), e portanto "ressignificando [visualmente] as ruínas não como objetos do olhar melancólico pós-imperial, mas como pontos de vista estratégicos para repensar as formações imperiais e seus significados contemporâneos" (Stoler, 2013; 2016). Por outras palavras, de acordo com a reflexão desenvolvida 
por Stoler, pensar com as ruínas imperiais - que no caso de Bonn seria um pensar visual - não significa tratar o artefato do Império como material morto ou como o resto de um antigo regime, mas trata-se de uma tarefa que visa observar como as ruínas são (re) apropriadas e, portanto, a posição estratégica e ativa dos destroços imperiais dentro de uma política do presente (Stoler, 2016). ${ }^{7}$ É justamente nesta perspectiva crítica e conceitual que as imagens de Maputo, Mombasa, Dar es Salaam, Merca, Watamu, Mogadíscio, entre outras, podem ser observadas, abordando a presença humana e marítima como elementos estéticos e conceituais estratégicos capazes de arruinar as ruínas (cf. ruination, to ruin; Stoler, 2013), sublinhando assim a reconfiguração vital e contemporânea dos restos inertes de impérios passados e suas ramificações em diferentes futuros (Stoler, 2016). Particularmente emblemáticas são, a meu ver, duas imagens: a primeira é a fotografia de uma mulher vestida de vermelho subindo os degraus da antiga catedral de Mogadíscio - obviamente um dos destroços do colonialismo italiano - (Figura 1) e a segunda é a vista de uma janela do Al-Aruba Hotel em Mogadíscio (Figura 2 e 3). Por um lado, o elemento humano - a mulher de vestido vermelho que percorre um atalho entre as

\footnotetext{
${ }^{7}$ É interessante notar como o prefácio ao livro de Jon Lee Anderson evidencie exatamente esta dimensão; ver Foreword in Bonn, $2015, \mathrm{~s} / \mathrm{p}$.
} 
ruínas da antiga catedral- e, por outro, a paisagem marítima - o Oceano Índico emoldurado pelas janelas do hotel - são os dois elementos estratégicos que destroem a melancolia que potencialmente determina o olhar das ruínas imperiais, apontando para a sua (re)significação vital e estratégica no presente, a partir de uma dimensão subjetiva.

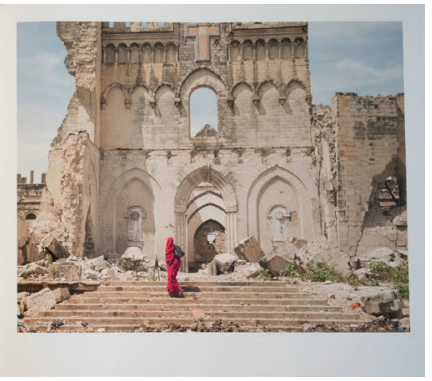

Figura 1. Fotografia da página do fotolivro The Mosquito Coast. Travels from Maputo to Mogadishu. (Bonn, 2015, s/p) A imagem pode ser acessada no website do fotógrafo: http://www.guillaumebonn.com/mosquito-coast.html (data da consulta: 5 de setembro de 2020). 


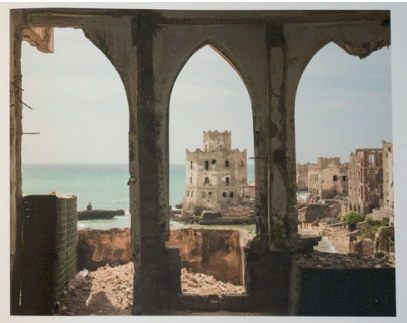

Figura 2. Fotografia da página do fotolivro The Mosquito Coast. Travels from Maputo to Mogadishu. (Bonn, 2015, s/p) A imagem pode ser acessada no website do fotógrafo: http://www. guillaumebonn.com/mosquito-coast.html (data da consulta: 5 de setembro de 2020).

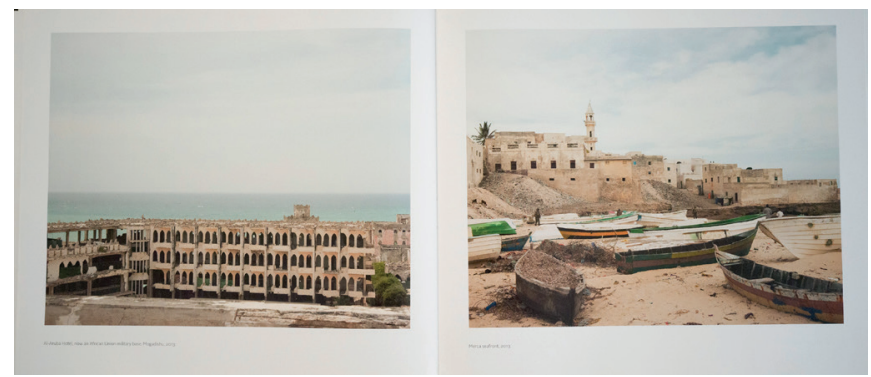

Figura 3. Fotografia da página do fotolivro The Mosquito Coast. Travels from Maputo to Mogadishu. (Bonn, 2015, s/p) A imagem pode ser acessada no website do fotógrafo: http://www. guillaumebonn.com/mosquito-coast.html (data da consulta: 5 de setembro de 2020). 
Sem entrar numa close reading das imagens - o que não constitui o objetivo da análise que pretendo desenvolver - gostaria de focar na primeira imagem que, segundo Bonn, remete a uma experiência real vivida no passado pelo fotógrafo que, através desta fotografia, (re)encena o acontecimento, colocando o sujeito humano retratado, a mulher, como elemento visual soberano, dominando e (re)significando os restos do colonialismo italiano e os rastos da guerra civil que nas últimas duas décadas atingiu o estado somali e, em particular, a cidade de Mogadíscio.

A segunda imagem é a do Hotel Al-Aruba em Mogadíscio, um edifício de origem colonial e antiga base das milícias de Al-Shabab, posteriormente transformado na base militar do contingente da União Africana que, em 2013, desenvolvia a missão de paz na Somália. 0 edifício antigo surge na fotografia como uma moldura que permite focar um outro nível da imagem, possibilitando uma mudança estratégica de uma topografia social para outra, determinada pelo foco nas pessoas no segundo plano da imagem, onde as janelas do edifício são utilizadas para evidenciar uma ação que acontece além e apesar dos escombros. A estratificação de experiências e de temporalidade que pauta ambas as imagens é o elemento decisivo para a definição da ruína não como um vestígio do passado, mas como um índice do presente e de um 
futuro possível. Portanto, observando o projeto fotográfico como um todo, é a relação entre os elementos marítimos e humanos que constituem o tecido de uma narrativa construída por diferentes camadas de histórias e memórias - sugerindo um contraponto explícito e produtivo com a escrita literária - e que por meio de uma linguagem visual constrói uma memória de si e do lugar seguindo uma estratégia conceitual que aponta para o que Achille Mbembe define como "formas africanas de auto-inscrição/escrita de si" (self-writing) (Mbembe, 2002). Por outras palavras: imaginações e estratégias que desmantelam uma ideia de autenticidade pautada por uma relação entre localidade, identidade e história, indicando, "um espaço intelectual para repensar aquelas temporalidades que [estão] sempre se bifurcando simultaneamente para vários futuros diferentes e assim fazendo abrem o caminho para a possibilidade de múltiplas ancestralidades" (Mbembe, 2002). Refiro-me, por exemplo, a obras como Paradise and By the Sea (2001) do escritor tanzaniano Abdulrazak Gurnah, Maps (2001) ou Links (2005) do escritor somali Nuruddin Farah, Índicos Indícios (2005) e Ponta Gea (2017) do romancista moçambicano João Paulo Borges Coelho. Trata-se de autores cujos projetos literários são marcados por uma relação paradigmática entre o tempo e a escrita de si e onde o mundo do Índico (cf. Indian Ocean World) aponta para uma geogra- 
fia subjetiva e transnacional através da qual outros tempos podem emergir, (re)apresentando histórias e memórias que revelam diferentes eu, e desmontando deste modo a ideia de uma identidade unívoca e que se assume como substância (Mbembe, 2002).

"Relíquias" e "Cidade Líquida" são respectivamente os títulos dos primeiros capítulos de By the Sea (Gurnah, 2001) e Ponta Gea (Borges Coelho, 2017), dois romances que, de forma distinta, articulam a constelação conceitual da ruína, da memória colonial, das transformações no presente e da escrita de si como matrizes narrativas onde a relação entre sujeito e tempo, e também entre a terra (o continente ou o estado-nação) e o mar (o oceano Índico) torna visível e (res)significa histórias que são, ao mesmo tempo, restos e índices de um mundo em transformação - temporal, espacial e humana - e por isso irremediavelmente pautado por desenvolvimentos combinados e desiguais (WReC, 2015). Por outra palavras, o que essas obras literárias parecem apresentar é uma ideia de mundo que as narrativas que geralmente substanciam a definição de uma subjetividade africana frequentemente negligenciam ou deixam de lado. Trata-se de aquilo que Achille Mbembe define como uma "África desligada do mundo: o sonho louco de um mundo sem outros" (20020 onde as fantasias primárias e a prosa do nativismo estão na base da 
tentativa de definir uma identidade africana de forma simples e clara e que, com o tempo, geralmente falharam. (Mbembe, 2002).

We are told that African history is essentially governed by forces beyond Africans' control. The diversity and the disorder of the world, as well as the open character of historical possibilities, are reduced to a spasmodic, unchanging cycle, infinitely repeated in accord with a conspiracy always fomented by forces beyond Africa's reach. Existence itself is expressed, almost always, as a stuttering. Ultimately, the African is supposed to be merely a castrated subject, the passive instrument of the Other's enjoyment. Under such conditions, there can be no more radical utopian vision than the one suggesting that Africa disconnect itself from the world - the mad dream of a world without Others. (Mbembe, 2002, pp. 251-252)

Ao mesmo tempo, esses romances aparentemente autobiográficos e memorialísticos podem ser tratados como formas literárias de escrita de si que aspiram a outra conceituação da noção de tempo em sua relação com a memória e a subjetividade em um quadro crítico pós-colonial ou, antes, pós-imperial. A meu ver, constituem formas de registro de si fora de uma concepção de tempo como espaço e da identidade como geografia (Mbembe, 2001) e onde o oceano 
Índico se configura como dispositivo conceitual, literário ou visual capaz de dar conta da densidade do presente africano e, portanto, o elemento para encarar o tempo como única subjetividade possível de ser escrita, imaginada e narrada.

2. Escrita de si, Estudos do Índico e Literatura-Mundial. A procura de novos pontos de partida.

A historical study centered on a stretch of water has all the charms but undoubtedly all the dangers of a new departure (Fernand Braudel).

Operacionalizando a relação entre espaço e história, de acordo com a reflexão proposta por Fernand Braudel (1985), a pesquisa nas áreas de História e Ciências Sociais sobre o Índico desenvolveu um conjunto de conceitos teóricos e de abordagens metodológicas que configuram o Oceano Índico como uma “arena inter-regional” (Bose, 2006: 6) e, portanto, como uma rede dinâmica e estruturada de relações (Chaudhury, 1990) cuja articulação privilegia contatos e dissonâncias entre estados-nações e regiões - mundo(s) - que são simultaneamente separados e contíguos. Tal como Sugata Bose aponta:

The Indian Ocean is better characterized as an "interregional arena" rather than as a 
"system", a term that has more rigid connotations. An interregional arena lies somewhere between the generalities of a "world system" and the specificities of particular regions. (Bose, 2006: 6)

A relação entre entidades regionais e sistema-mundo que a definição do Oceano Índico como uma "arena" pressupõe se baseia na necessidade de problematizar construções que projetam o que vem sendo definido como colonialidade do saber:

Regional entities known today as the Middle East, South Asia and Southeast Asia which underpin the rubric of Area Studies in the Western academy, are relatively recent constructions that arbitrarily project certain legacies of colonial power onto the domain of knowledge in the post-colonial era. The world of the Indian Ocean, or for that matter, that of the Mediterranean, has a much greater depth of economic and cultural meaning. Tied together by webs of economic and cultural relationships, such arenas nevertheless had flexible internal and external boundaries. These arenas, where port cities formed the nodal points of exchange and interaction, have been so far mostly theorized, described, and analyzed only for the premodern and early modern periods. They have not generally formed the canvas on which scholars 
have written histories of modern era. (Bose, 2006:, pp. 6-7)

Por outras palavras, a dimensão espacial aparece tão paradigmática quanto essencial para uma análise histórica, social e econômica, evidenciando um conjunto de especificidades que caracterizam a assim chamada arena do Índico. Ao mesmo tempo, para uma análise literária a perspectiva do Índico beneficiaria de uma abordagem crítica que permita a observação do espaço do Índico através de uma perspectiva materialista com o intuito de entender e analisar as realidades combinadas e desiguais que compõem o Mundo do Oceano Índico (cf. Indian Ocean World) sem recorrer à conceitos algo problemáticos - como os de universalismo ou modernidades alternativas (Hofmeyr, 2007) - que tem pautado as formulações críticas e conceituais no âmbito dos estudos do Índico cujo embasamento teórico pressupõe a existência de uma noção de universal e de moderno de matriz mais espacial e temporal de que relacional. ${ }^{8}$ Levando adiante esta linha de reflexão, uma perspectiva ulterior parece surgir. A dimensão mundana - wordling - (Said, 1993 e 2004) do tempo e da subjetividade que caracteriza as narrativas literárias e visuais

${ }^{8}$ Sobre a dimensão relacional e não geográfica ou histórica das categorias de moderno, modernidade, modernização, entre uma vasta bibliografia, veja-se: Jameson, 2002, Harootunian, 2000; WReC, 2015. 
analisadas neste ensaio oferece a possibilidade de estabelecer um diálogo entre os debates que pautam os Estudos do Oceano Índico o os mais recentes desdobramentos críticos no âmbito dos estudos sobre Literatura-Mundial de acordo com as propostas teóricas desenvolvidas pelo Coletivo de Pesquisa de Warwick [Warwick Research Collective - WReC] no ensaio Combined and Uneven Development. Towards a New Theory of World-Literature (WReC, 2015) cuja edição brasileira em língua portuguesa acaba de ser publicada pela Editora da Unicamp (Coletivo de Pesquisa de Warwick, 2020). Penso, sobretudo, nas discussões em torno dos conceito de modernidade/ modernismo/modernização e de sistema-literário mundial, bem como nas questões relativas às noções de centro/(semi-)periferia do qual desembocam as categorias de romance semi-periférico e de realismo semi-periférico - (semi-)peripheral novel / (semi-) peripheral realism - propostos pelo WReC e, neste sentido, gostaria de voltar novamente a uma das imagens que compõem o fotolivro de Guillaume Bonn (Figura 4). 


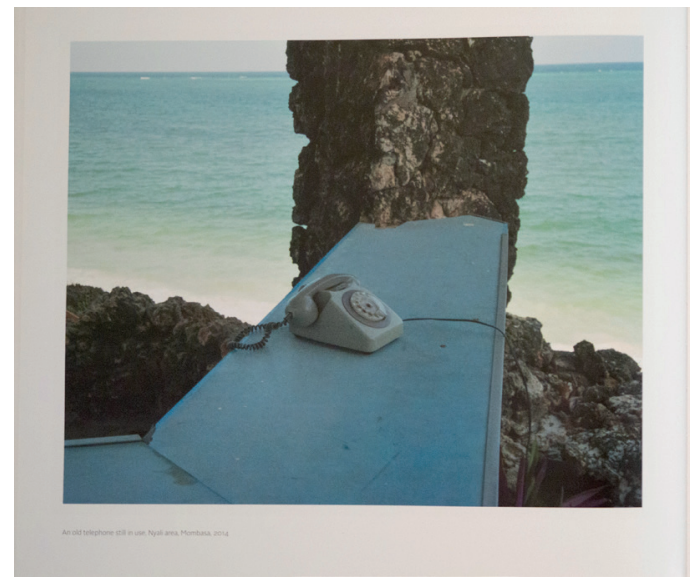

Figura 4. Fotografia da página do fotolivro The Mosquito Coast. Travels from Maputo to Mogadishu. (Bonn, 2015, s/p) A imagem pode ser acessada no website do fotógrafo: http://www. guillaumebonn.com/mosquito-coast.html (data da consulta: 5 Setembro 2020).

As ideias de progresso, consumismo, transformação e metamorfose que o fotógrafo menciona nos excertos antes citados resultam evidentes no Projeto e também aparecem como sendo aspecto paradigmáticos dos textos literários dos autores habitualmente definidos como escritores do Índico qual é o caso de By the Sea de Abdulrazak Gurnah (2001) e Ponta Gea de João Paulo Borges Coelho (2017). ${ }^{9}$ Para além

${ }^{9}$ Para uma leitura de Ponta Gea no âmbito da perspetiva crítica desenvolvida pelo WReC, veja-se Paulo de Medeiros, "The Drow- 
disso, observando o trabalho de Bonn, bem como os romances de Gurah e Borges Coelho, uma original compreensão do que vem sendo definido como Mundo do Índico parece surgir, oferecendo a possibilidade de abordar as discussões que concernem as narrativas e os Estudos do Oceano Índico dentro do debate proposto pelo WReC em torno da ideia de mundo no campo da literatura-mundial e suas implicações dentro do debate sobre Literatura Comparada. Na impossibilidade de desenvolver uma discussão mais ampla e detalhada dos dois romances - cuja densidade e complexidade mereceriam uma análise aprofundada que as limitações deste texto não me permite abordar - gostaria de me deter nas implicações disciplinares que a ideia do mundo contida nessas obras literárias e visuais parece sugerir, para desenvolver algumas reflexões críticas e disciplinares que, a meu ver, são particularmente relevantes para o argumento que procuro esboçar nas conclusões deste texto e que se encontram alegoricamente ilustradas pela fotografia de Bonn: um antigo telefone colocado ao ar livre, ainda em perfeito funcionamento, e aparentemente conectado ao Oceano Índico. Uma "imagem[ns] dialética[s] de desigualdade combinada que requerem não apenas uma simples decodificação,

ning of Time: Ecological Catastrophe, Dialectics, and Allegorical Realism in João Paulo Borges Coelho's Ponta Gea and Água: Uma novela rural" in Brugioni, et al 2020, pp. 219-247 
mas uma aplicação criativa". (Coletivo de Pesquisa de Warwick, 2020, p. 43)

Em primeiro lugar, nessa perspectiva, parece-me que a reflexão sobre as literaturas do Oceano Índico em uma dimensão sistêmica (Moorthy \& Jamal, 2010) se beneficiaria profundamente de uma intersecção com a problematização proposta pelo WReC sobre o sistema-literário mundial a ser entendido como toda a literatura que registra o sistema-mundo capitalista moderno (WReC, 2015) e, ao fazê-lo, oferece a possibilidade de reconhecer formas literárias específicas que são capazes de dar conta dos desenvolvimentos combinados e desiguais da modernidade como o sensorium espaço-temporal do capitalismo (Jameson, 2002; WReC, 2015).

Tal como a entendemos, a "registração" literária do sistema-mundial não envolve (necessariamente) crítica ou dissidência. Em vez disso, nossa suposição é a de que a efetividade do sistema-mundial será necessariamente discernível em qualquer obra literária moderna, uma vez que o sistema-mundial existe imprescindivelmente como a matriz dentro da qual toda a literatura moderna surge e toma forma. (Coletivo de Pesquisa de Warwick, 2020, p. 49)

(...) 
Mas as reflexões dos textos (semi)periféricos sobre o mundo são necessariamente performadas no forte reflexo do passado e do presente das dispensações coloniais e imperiais, sejam quais forem as proveniências nacionais, transnacionais ou regionais específicas dessas dispensações: inglesas, francesas, espanholas, otomanas, soviéticas/russas, americanas, e assim por diante. (Coletivo de Pesquisa de Warwick, 2020, p. 100)Talvez possamos então ver as dinâmicas de "dobragem e pressão" ou "telescópicas" do desenvolvimento combinado e desigual como uma forma de viagem no tempo dentro do mesmo espaço, uma criação de pontes espaciais entre tempos distintos - uma produção de espaço extemporâneo, no sentido de Lefebvre - que vai das formas clássicas de realismo do século XIX até as metodologias especulativas da ficção científica mais contemporâneas. (Coletivo de Pesquisa de Warwick, 2020, p. 44) ${ }^{10}$

${ }^{10}$ Devido à impossibilidade de incluir as notas de tradução relativas a conceitos e expressões impossíveis de serem traduzidas literalmente e algo complexa a novel conceitual, veja-se a citação em sua versão original: "We might then see the 'accordionising' or 'telescoping' function of combined and uneven development as a form of time travel within the same space, a spatial bridging of unlike times - in Lefebvre's sense, the production of untimely space - that leads from the classic forms of nineteenth-century realism to the speculative methodologies of today's global science fiction". (WReC, 2015: 17) 
Além disso, considerando o debate sobre o Oceano Índico e, portanto, a teorização sobre as literaturas do Oceano Índico no quadro da análise do sistema-mundo, uma perspectiva crítica baseada na ideia do Oceano Índico como Mundo e simultaneamente como paradigma mundano (cf. wordly; Said, 2004) tratando-se em ambos os caso de conceito estabelecidos no âmbito dos Estudos do Oceano Índico (IOS) - permitirá abordar o Mundo do Índico - e, portanto, as literaturas do Oceano Índico - não como "um campo nivelado pela igualdade" (WReC, 2015; Coletivo de Pesquisa de Warwick, 2020) e, portanto, examinar uma série de aspectos hegemônicos e eurocêntricos que, à semelhança do debate sobre Literaturas Comparadas, precisam ser abordados e problematizados também no campo dos estudos literários do Oceano Índico. Entre muitos aspectos que poderiam ser trazidos aqui, gostaria de enfocar a questão linguística - que também está relacionada à ideia do Oceano Índico como um paradigma mundano e transcultural (Brugioni, 2017) - abordando um aspecto bastante paradigmático representado pela marginalidade de autores e textos "lusófonos" no campo dos estudos sobre as literaturas do Oceano Índico. Observando a publicação académica sobre literaturas do Oceano Índico desde, pelo menos as últimas décadas, a ausência de sujeitos, espaços e obras - literárias e críticas - de língua portuguesa nos estudos culturais e 
literários sobre o Oceano Índico é um aspecto bastante visível, evidenciando como os poucos autores "lusófonos" incluídos sejam apenas aqueles cujos romances foram traduzidos para o inglês, qual é o caso, por exemplo, de Mia Couto. À semelhança da situação que caracteriza a Literatura Comparada como campo de estudo, é possível notar que o campo dos estudos literários do Oceano Índico parece precisar de se envolver de forma mais engajada com a diversidade linguística combinada e desigual que lhe é intrínseca através de uma ideia e de uma prática de escrita e tradução mais progressista e eficaz, evitando deste modo o fetichismo da linguagem e, sobretudo, reconhecendo o continuum entre a prática da escrita e da tradução que pauta a literatura no Índico africano.

Se ler é sempre também "traduzir", então as sementes já estão plantadas para a visão de que, mesmo que a tradução seja por definição um ato "político", algo pode ser adquirido com isso, e não apenas perdido. Somos ainda intimados por esse insight a compreender a leitura e a tradução como processos sociais, em vez de solitários, e portanto a atender à gama completa de práticas sociais implicadas: escrita enquanto trabalho mercadorizado, a elaboração de livros, a publicação e o marketing, o "destino" social de uma publicação (resenhas, crítica, a procura por, cria- 
ção e cultivação de um público leitor etc.). (Coletivo de Pesquisa de Warwick, 2020, pp. 61-62)

Relacionado a este aspecto, vem o meu segundo ponto. Levando em consideração a proeminência do gênero literário usualmente definido como autobiográfico, da auto-ficção ou da escrita de si no mundo do Oceano Índico, essa perspectiva teórica permitirá qualificar melhor as formas literárias do Oceano Índico e, particularmente, citando novamente o Coletivo de Pesquisa de Warwick:

Para compreender a literatura-mundial como a registração literária da modernidade sob o signo do desenvolvimento combinado e desigual, devemos tratar de seus modos de compressão espaço-temporal, da justaposição de ordens assíncronas e níveis de experiência histórica, de suas indicações barométricas de forças invisíveis atuando à distância no local e no familiar - na medida em que esses elementos se manifestam por meio de estratégias estéticas, gêneros e formas literárias. Qualquer tipologia de desenvolvimento combinado e desigual oferecerá um catálogo de efeitos ou motivos no nível da forma narrativa: encontros discrepantes, efeitos de alienação, ligações e travessias surreais, objetos estranhos não identificados, improváveis semelhanças entre barreiras linguís- 
ticas, temporais e territoriais: o equivalente a guarda-chuvas encontrando máquinas de costura em (animadas) mesas de dissecação.** São essas, essencialmente, imagens dialéticas de desigualdade combinada que requerem não apenas uma simples descodificação, mas uma aplicação criativa. (Coletivo de Pesquisa de Warwick, 2020, p. 43) ${ }^{11}$

Em conclusão, esta intersecção crítica permitiria reposicionar os estudos do Oceano Índico, e particularmente seus desdobramento no campo dos estudos literários, dentro da vasta perspectiva crítica do sistema literário-mundial não como uma literatura mundial maior - como diria Franco Moretti (2013), mas como formas literárias (semi-)periféricas que registram transformações e mudanças contemporâneas e, ao fazê-lo, oferecem a possibilidade de repensar os diferentes níveis de

${ }^{11}$ Citação no original: "To grasp world-literature as the literary registration of modernity under the sign of combined and uneven development, we must attend to its modes of spatio-temporal compression, its juxtaposition of asynchronous orders and levels of historical experience, its barometric indications of invisible forces acting from a distance on the local and familiar - as these manifest themselves in literary forms, genres and aesthetic strategies. Any typology of combined and uneven development will offer a catalogue of effects or motifs at the level of narrative form: discrepant encounters, alienation effects, surreal cross-linkages, unidentified freakish objects, unlikely likenesses across barriers of language, period, territory - the equivalent of umbrellas meeting sewing machines on (animated) dissecting tables. These are, in essence, dialectical images of combined unevenness requiring not just simple decoding but creative application." (WReC, 2015: 17). 
experiências históricas e as improváveis semelhanças de narrativas que caracterizam a escrita literária no Oceano Índico. Além disso, esse tipo de (re)visão crítica e conceitual contribuiria também para desmantelar uma série de concepções eurocêntricas e essencialistas que frequentemente definem as abordagens críticas e a formulação teórica nos estudos literários contemporâneos dedicados a escritores e narrativas do Oceano Índico. Portanto, abordar as literaturas do Oceano Índico ou, melhor, as narrativas (visuais) e as escritas (literária) do Índico como formas de registro do sistema-mundial capitalista moderno contribuiria possivelmente para uma mais profunda compreensão material da ampla gama de combinações(s) e desigualdades(s) que caracterizam o sistema-literário mundial e portanto também as literaturas do Oceano Índico.

Referências

BONN, G. The Mosquito Coast. Travels from Maputo to Mogadishu. Hatje Cantz, 2015.

BONN, G. http://www.guillaumebonn.com/mosquito-coast.html (5th of July 2020);

BORGES COELHO, João Paulo. Ponta Gea. Caminho, 2017. BORGES COELHO, João Paulo Índicos Indícios I - Setentrião. Caminho, 2005.

BORGES COELHO, João Paulo Índicos Indícios II - Meridião. Lisboa: Caminho, 2005. 
BOSE, S. A Hundred Horizons: The Indian Ocean in an Age of Global Imperialism. Harvard University Press, 2006.

BRAUDEL, Ferdinad La Méditerranée, vol. 1: L'espace et l'histoire, vol. 2: Les hommes et l'héritage. Flammarion, 1985.

BRUGIONI, E., GROSSEGESSE, O., MEDEIROS, P. de. (orgs). A Companion to João Paulo Borges Coelho. Rewriting the (Post)colonial Remains. Peter Lang, 2020.

BRUGIONI, E. Literaturas Africanas Comparadas. Paradigmas e Representações em contrapontos. Editora Unicamp, 2019.

BRUGIONI, E. "Writing from Other Margins. Difference, Exception, and Translation in the Portuguese-speaking World: Counterpoints between literary representations and critical paradigms". CADERNOS DE TRADUÇÃO, 37 (1), 2017, p. 65-89. DOI: http:// dx.doi.org/10.5007/2175-7968.2017v37n1p65.

CARVALHO, R. D de. (2005) As paisagens propícias. Cotovia, 2005

CHAUDHURY, K. N. (1990) Asia before Europe: Economy and Civilization of the Indian Ocean from the rise of Islam to 1750. Cambridge University Press, 1990. COLETIVO DE PESQUISA DE WARWICK. Desenvolvimento Combinado e Desigual. Por uma nova teoria da Literatura-Mundial. Tradução Gabriela Beduschi Zanfelice. Introdução à Edição Brasileira: Elena Bru- 
gioni, Alfredo Cesar Melo, Paulo de Medeiros. Campinas: Editora Unicamp, 2020.

FARAH, N. Links. Penguin Books, 2005.

FARAH, N. Maps. Penguin Books, 2001.

FAWAZ, L. T. et al. (eds.) (2002) Modernity and Culture: From the Mediterranean to the Indian Ocean. Columbia University Press, 2002.

FRANK, A. G. \& GILLS, B. K., "The Five Thousand Year World System in Theory and Praxis" in Denemark, R. et al. World System History: Social Science of Long Term Change. Routledge, 2000. p. 3-23.

FRANK, A. G. (1998). ReOrient: Global Economy in the Asian Age. University of California Press, 1998.

GUPTA, P., Hofmeyr I. \& PEARSON M. (Eds.) (2010) Eyes Across the Water. Navigating the Indian Ocean. Unisa Press \& Penguin India, 2010.

GURNAH, A. By the Sea. Bloomsbury, 2001

GURNAH, A. Paradise. New Press, 1994.

HOFMEYR, Isabel. "The Black Atlantic meets The Indian Ocean: Forging New Paradigms for transnationalism for the Global South. Literary and Cultural Perspectives", Social Dynamics. A Journal of African Studies, 33 (2), 2007, p. 3-32,.

HAROOTUNIAN, Harry. History's Disquiet: Modernity, Cultural Practice, and the Question of Everyday Life. New York: Columbia University Press, 2000. KEARNEY, M. The Indian Ocean in World History. Routledge, 2004. 
JAMESON, F. Singular Modernity: Essay on the Ontology of the Present. Verso, 2002.

MBEMBE, A. \& SARR, Felwine (eds.). Écrire l'AfriqueMonde. Philippe Rey/Jimssan, 2017.

MBEMBE, A. "African Modes of Self-Writing" Public Culture 14.1, 2002, p. 239-273.

MCPHEARSON, K. The Indian Ocean: A History of People and the Sea. Oxford University Press, 1993.

MEDEIROS, P. de "11 1/2 Tese sobre o conceito de Literatura-Mundial" In Via Atlântica, São Paulo, 35, 2019, p. 307-331, JUL/2019

MORETTI, Franco. Distant Reading. Verso, 2013.

MOORTHY, S. \& JAMAL, A. (eds.). Indian Ocean studies: cultural, social, and political perspectives. Routledge, 2010.

PINTO RIBEIRO, A. África, os Quatros Rios. A representação de África através da literatura de viagens europeia e norte-americana. Afrontamento, 2017.

SAIID, Edward W. Humanism and Democratic Criticism. Oxford University Press, 2004.

SAIID, Edward W. Culture and Imperialism. Vintage Books, 1993.

SONTAG, Susan. On photography. Penguin Book, 1997.

STOLER, A. L. Duress. Imperial Durabilities in our Time. Duke University Press, 2016.

STOLER, A L Imperial Debris: On Ruins and Ruination.

Duke University Press, 2016. 
WALLERSTEIN, I. World-Systems Analysis: An Introduction. Duke University Press, 2004. WARWICK RESEARCH COLLECTIVE (WReC). Combined and Uneven Development: Towards a New Theory of World-Literature. Liverpool: Liverpool University Press, 2015. 